\title{
APPROACH TO 3D ANALYSIS OF GRAVITY PTOSIS
}

\author{
R.A. Guryanov ${ }^{\mathrm{a}}$, S. Monkin ${ }^{\mathrm{b}}$, A.Monkin ${ }^{\mathrm{b}}$, A.Petrov $^{\mathrm{b}}$ \\ ${ }^{\text {a }}$ Department of plastic surgery, Sechenov First Moscow State Medical University, robert.gurianov@ gmail.com \\ ${ }^{\mathrm{b}}$ CM Systems LLC
}

Commission II, WG II/10

KEY WORDS: gravity ptosis, plastic surgery, SMAS-lifting, ageing

\begin{abstract}
:
The assessment of ptosis degree for rejuvenation procedures, the choice of following operation technique and evaluation of surgery result are based on subjective visual examination and surgeon's experience.

The photogrammetric scans of 25 female patients of age 20 to 55 in vertical and supine (horizontal) position of body with placing the regular marker points on the face were analyzed. For 5 patients, also the CT data was acquired and segmentation of soft tissue was performed. Four of these patients underwent SMAS-lifting, the photogrammetry scanning was repeat 6 months after the operation. Computer vision algorithms was used for markers detection on the 3D model texture, marker were projected from texture to triangular mesh. 3D mesh models were registered with user defined anatomy points and pair selection based on markers location was done. Pairs of points on vertical and horizontal 3D models were analyzed for surface tissue mobility examination.

The migration vectors of each side of the face are uniformly directed upwards and laterally. The vectors are projected at the areas of so-called ligaments demonstrate no evidence in deviation from row sequences.

The volume migration is strongly correlates with the age of examined patients, on the contrary the point migration moderately correlates with age in patients of 30 to 50 years old.

The analysis of migration vectors before and after the SMAS-lifting revealed no significant changes in surface points' migration. The described method allows to assess the mechanical conditions of individual face and evaluate efficacy of surgery. This approach can be used for the classification of face ptosis grade.
\end{abstract}

\section{INTRODUCTION}

The rules of soft tissue framework mechanics are the significant interest for fundamental anatomy and plastic surgery as an insight and development ground for surgical approaches and technics. The use of non-contact imaging methods as the photogrammetry or computed tomography allow to perform non-invasive anatomical and functional analysis on the living persons in $3 \mathrm{D}$ without deformation of the object of study. In the modern plastic surgery, the doctrine of facial ligaments and supporting connective tissue structures is predominant in view on the aging mechanisms and rejuvenation procedures (Furnas, 1989, Furnas, 1994, Farkas, 2013, Mendelson, 2008, Ozdemir R., 2002). Nevertheless, the basis of these views is absolutely empiric and grounded on the anatomical dissection and surgical experience. The evidences of ligaments presence and their functional role using the layered anatomical dissection technics is not standing up to criticism because this approach leads to demolishing of physiological tissue relationship, not mention the subjective and biased approach to preparation technique (Santos, 2016). In fascial anatomy and topography, the slicing or tomographic principle is only capable to verify the morphological findings (Gardetto, 2003).

The analysis of 3-dimensional data acquired during performing of the functional tests allows to prove the veracity of knowledge of soft tissue framework from the one hand and can be the ground and criteria of presence and significance of morphological findings from the other. 3D analysis requires to develop the specific approach to measurement technique and methods (Weaver, 2010, Kim,2015).

At the current study, our approach implies that the skull with some thick and dense fasciae and muscles (as masseter and temporal muscle) are considered as a rigid framework, covered by the deformable soft tissues. In some modern anatomical concepts, the dense connections or adhesions between the bony framework and skin are distinguished and named ligaments. These ligaments are supposed to suspend the soft tissues and skin and possibly may restrict the sagging and deformation of the soft tissue under the gravity force. Aging and ptosis lead to alteration of mechanical properties of the facial soft tissues, thus we proposed to access the deformation caused by the changing of gravity force vector between patient vertical and horizontal positions.

\section{MATERIALS AND METHODS}

The study is based on the gravity test - the functional test when the patient undergoes the photogrammetry scanning (Artec Eva) in vertical (standing) and horizontal (lying) position, the change of gravity vector leads to passive deformation of the soft tissues (Guryanov, 2015, Ozsoy, 2015). Before the scanning, the marker points are placed on the skin surface to register their migration. The acquired 3D models are aligning by the defining points and surfaces strongly connected to underlying hard framework (medial canthus, columella, forehead area).

For the soft tissue mobility study 20 patients in the age of 20 to 55 years old were analyzed, three of them underwent the SMAS-lifting and scanning was repeated 6 months after the operation. The point migration, volume changes patterns and the shortest distances between surfaces were assessed. For 5 patients, also the CT data was acquired and segmentation of soft tissue volume was performed, the soft tissue thickness analysis, migration vectors and volume changes were compared to reveal the dependence between the parameters. 
The displacement of a marker point can be presented as the migration vector. To access and measure the migration vectors the following procedures has being performed:

1. detection of the marker points on the models (automatically, manually)

2. matching the points

3. computing the distances between matched points

\subsection{Texture rewrapping}

Initial texture is a set of disconnected fragments. Rewrapping is performed using the Blender. The $3 \mathrm{~d}$ model is unwrapped on a plane, pixels from initial texture are translated on this plane (Figure 1, Figure 2)

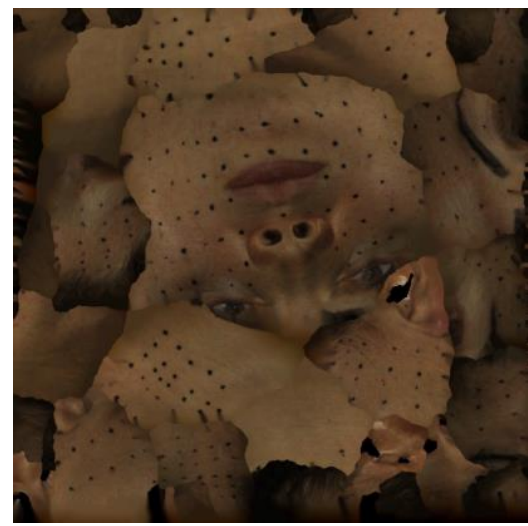

Figure 1. Initial texture

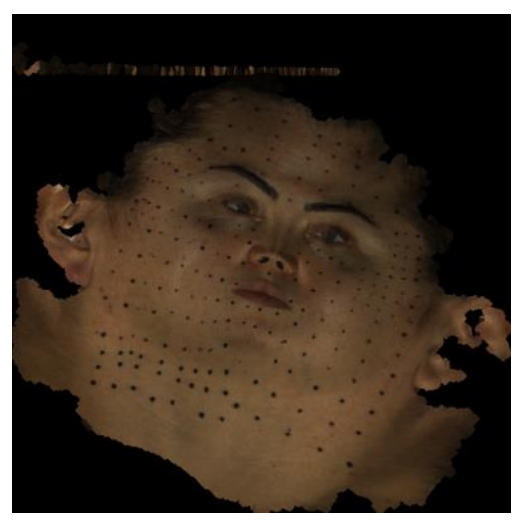

Figure 2. Rewrapped texture

\subsection{Markers detection}

OpenCV is used to markers detection. Contours on the texture are automatically detected by using the Canny edge detection algorithm. Connected components of texture pixels are found by the contours. The components are eliminated if they exceed a given scale. The marker positions on the texture are computed as the centers of the components (Figure 3).

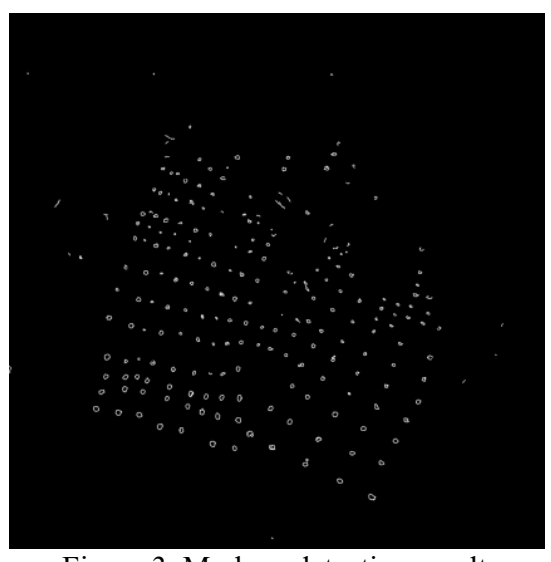

Figure 3. Markers detection result.

\subsection{Markers matching}

Markers matching in $3 \mathrm{~d}$ space is performed using the Coherent Point Drift nonrigid registration algorithm. CPD [https://github.com/gadomski/cpd] implementation of this algorithm are used. A marker set from the first $3 \mathrm{~d}$ model is registered to a marker set of the second $3 \mathrm{~d}$ model. For each marker from the first set the pair marker is computed as a closest marker from the second set. The figure 5 and figure 6 represent the set of the first model markers registered to the set of the second model markers.

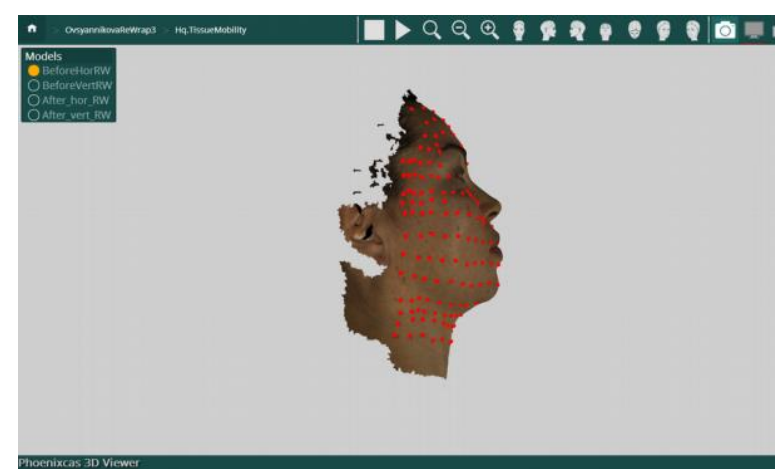

Figure 4. Selected markers, model 1

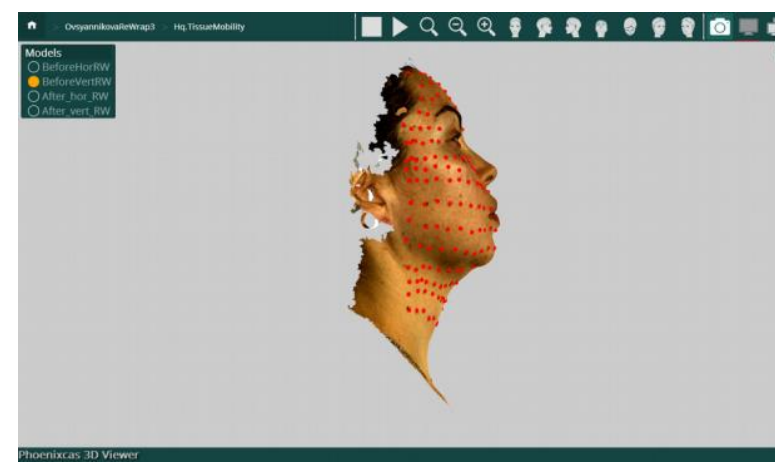

Figure 5. Selected markers, model 2

\subsection{Distances}

Visualization and calculation of the vectors constructed by the paired markers. 


\section{RESULTS}

The point placement accuracy of point placement was performed and amounted to $0.4 \mathrm{~mm}$. The relative displacement of points in explored regions was $0.2 \pm 0.5 \mathrm{~mm}$, thus the method accuracy does not allow to evaluate the slight relative displacement of points on the skin surface, therefore in current study we consider that the relative point migration is negligible. The mean value of migration vectors lengths was 4.15 to $6.43 \mathrm{~mm}$, the moderate correlation revealed between the mean migration vector value and age of patient. The patients underwent the SMAS-lifting demonstrated the decrease of the migration vectors lengths about $0.8 \mathrm{~mm}$. The declination of mean migration vector from the sagittal plane and Frankfort horizontal plane was $26,6^{\circ}-35,8^{\circ}$ and $34,3^{\circ}$ $49.9^{\circ}$ respectively, in the patients after SMAS-lifting the declination from sagittal plane and Frankfort plane changed by $7,22^{\circ}$ and $-0,44^{\circ}$ respectively. Thus, the orientation of vectors is uniform in every individual so the migration of points occur predominately in upper-lateral direction (Figure 6).

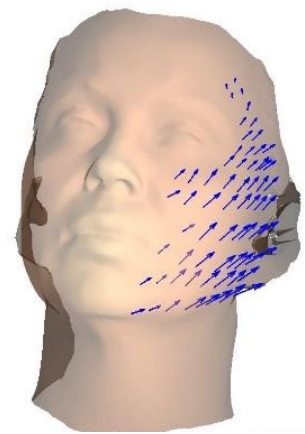

Figure 6. Skin point migration vectors

The migration ability of skin surface linearly decreases along the direction to the temporal area in all patients. Analysis of soft tissue thickness demonstrates its increasing under the zygomatic arch and in cheek area. The correspondence between the soft tissue thickness was analyzed by correlational analysis. (Table 1)

\begin{tabular}{|c|c|c|c|c|}
\hline Region & $\begin{array}{l}\text { Migratio } \\
\text { n ability }\end{array}$ & $\begin{array}{l}\text { Volume } \\
\text { migratio } \\
\mathrm{n}\end{array}$ & $\begin{array}{l}\text { Soft } \\
\text { tissue } \\
\text { thickn } \\
\text { ess }\end{array}$ & $\begin{array}{l}\text { Migration } \\
\text { ability and } \\
\text { soft tissue } \\
\text { correlation }\end{array}$ \\
\hline Temporal & $\begin{array}{l}\text { Low } \\
2-4 \mathrm{~mm}\end{array}$ & $\begin{array}{l}\text { Low } \\
0,2-2,5 \\
\text { mm }\end{array}$ & $\begin{array}{l}\text { Thin } \\
3-4 \\
\mathrm{~mm}\end{array}$ & $\begin{array}{l}\text { High } \\
0,76\end{array}$ \\
\hline $\begin{array}{l}\text { Zygomati } \\
\mathrm{c} \text { arch }\end{array}$ & $\begin{array}{l}\text { Low } \\
5-6 \mathrm{~mm}\end{array}$ & $\begin{array}{l}\text { Low } \\
0,2-2,5 \\
\text { mm }\end{array}$ & $\begin{array}{l}\text { Thin } \\
4-5 \\
\mathrm{~mm}\end{array}$ & $\begin{array}{l}\text { High } \\
0,81\end{array}$ \\
\hline $\begin{array}{l}\text { Parotideo } \\
\text { masseteric } \\
\text { area }\end{array}$ & - & - & - & - \\
\hline $\begin{array}{r}\text {-upper } \\
\text { half }\end{array}$ & $\begin{array}{l}\text { Medium } \\
6-8 \mathrm{~mm}\end{array}$ & $\begin{array}{l}\text { High } \\
2,5-8,5 \\
\mathrm{~mm} \\
\end{array}$ & $\begin{array}{l}\text { Thick } \\
7-9 \\
\mathrm{~mm}\end{array}$ & $\begin{array}{l}\text { Low } \\
0,41\end{array}$ \\
\hline $\begin{array}{r}\text {-lower } \\
\text { half }\end{array}$ & $\begin{array}{l}\text { High } \\
8-11 \\
\mathrm{~mm}\end{array}$ & $\begin{array}{l}\text { Medium } \\
\text { 4-7 mm }\end{array}$ & $\begin{array}{l}\text { Mediu } \\
\mathrm{m} \\
5-6 \\
\mathrm{~mm} \\
\end{array}$ & $\begin{array}{l}\text { High } \\
0,73\end{array}$ \\
\hline
\end{tabular}

Table 1. Migration of skin surface, volumes and soft tissue thickness

The volume migration is strongly correlates with the age of examined patients, on the contrary the point migration moderately correlates with age in patients of 30 to 50 years old, what can be explained by the different rate of soft tissue ageing.

The volume migration was assessed by surface difference distances and patterns. The main regions of volume enhancement were the upper-posterior quadrant of parotideomasseteric area (maximum $2.5 \mathrm{~mm}$ in age of 20 to 33 , reaching $8.5 \mathrm{~mm}$ after 34 years old) and the temporal area (maximum 1,2 $\mathrm{mm}$ in the age of 20 to 33 . reaching $3,2 \mathrm{~mm}$ after 34). The main region of volume diminution is the cheek area, maximal difference reaches from $4,7 \mathrm{~mm}$ in a group younger than 33 years old to 8,5 in older. The broadening of volume migration patterns and distances corresponds with increasing age (Figure 7, Figure 8). The analysis of migration vectors before and after the SMAS-lifting revealed no significant changes in surface points migration, but the slightly discernable decreasing of volume migration value (about 0,8 $\mathrm{mm}$ ). The counters of volume migration patterns distorted after SMAS-lifting.
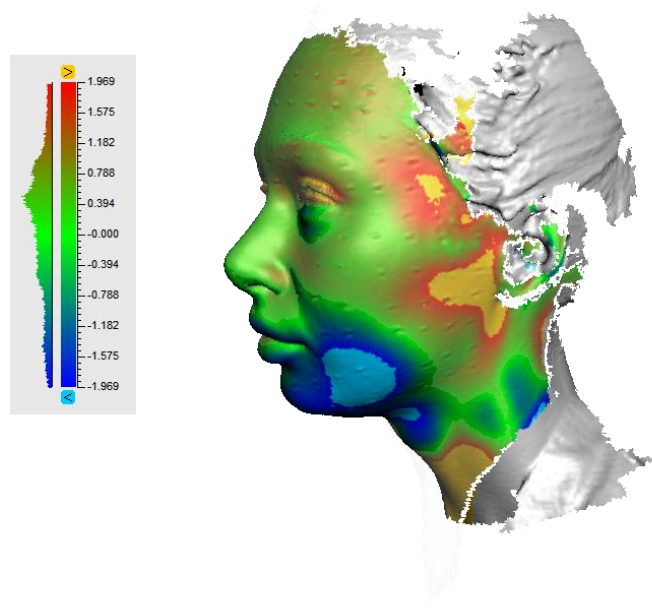

Figure 7. Patient E., 26 years old. Patterns of volume migration
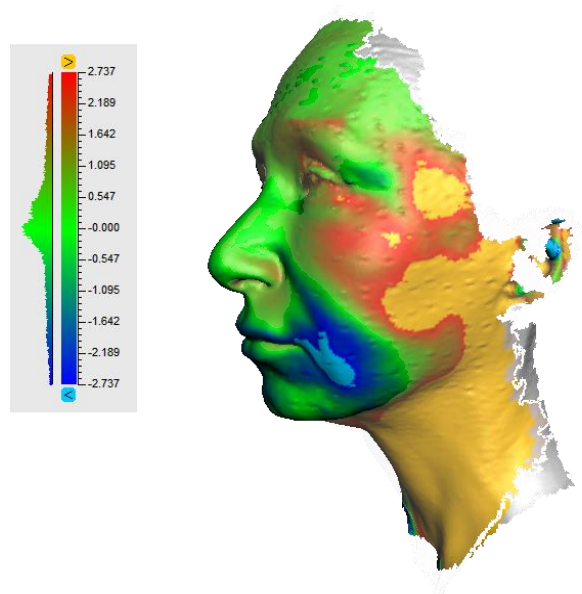

Figure 8. Patient H., 26 years old. Patterns of volume migration 


\section{DISCUSSION}

The direction and length of migration vector can be considered as the integral migration ability index, the vectors are distributed uniformly. Since it was surmised that relative displacement of points is negligible the observing deformation may be considered as a shift.

Analysis of points migration, volume migration and soft tissue thickness showed that the skin points migration occur independently from underlying soft tissue, thus the skin movement is not constricted by any known ligaments and tissue adhesions (Furnas, 1989, Furnas, 1994, Mendelson, 2008). The volume migration is more variable from region to region of lateral face: the migration of volumes is prominent in the whole parotideomasseteric and cheek area and delimited only over the zygomatic arch, posterior border of $\mathrm{m}$. depressor anguli oris and at orbicularis oculi border. Volume migration values correlates with the soft tissue thickness.

Diagram 1 reflect the skin surface points migration before and after the SMAS-lifting, volume migration and soft tissue thickness in a vertical slice on the middle of zygomatic arch. Skin migration before and after the operation changed insignificantly (about $0,8 \mathrm{~mm}$ ) resembling the linear function.

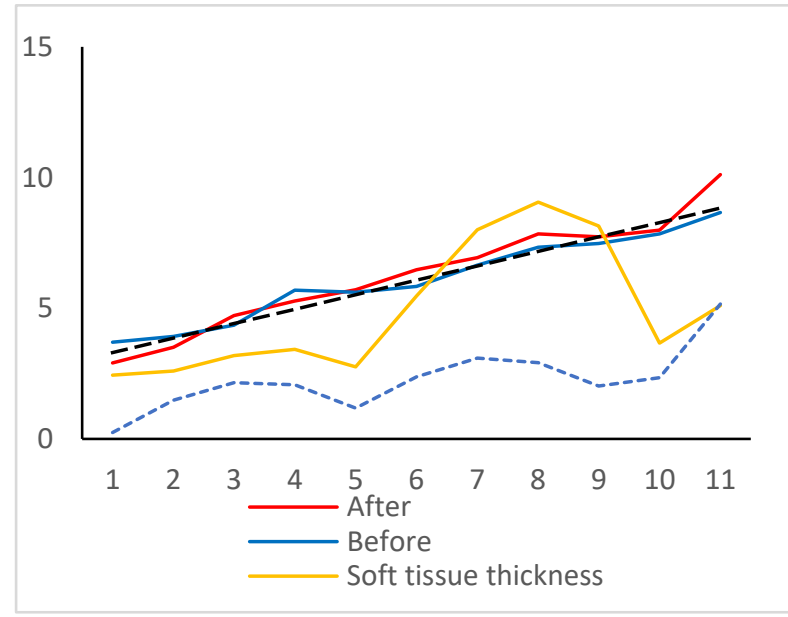

Diagram 1. Surface points migration before and after SMASlifting

Soft tissue thickness and volume migration do not correspond with skin migration. The migration of volumes (Figure 8, Figure 9) are slightly distorted after the operation, but the change of volume migration ability is minimal (about $1 \mathrm{~mm}$ ).

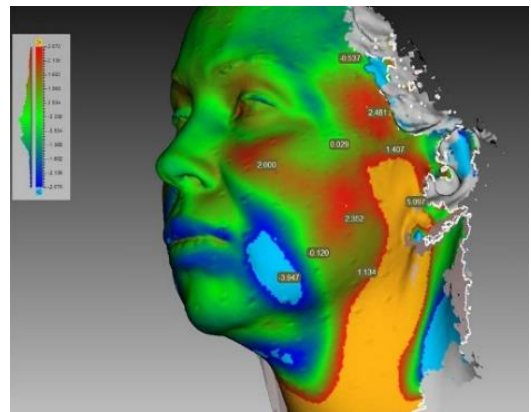

Figure 9. Patterns of migration and difference values before the SMAS-lifting

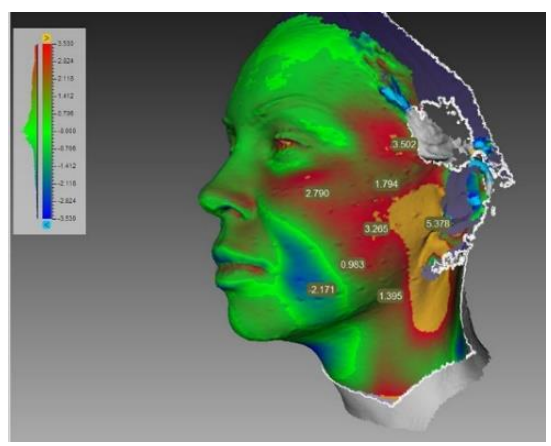

Figure 10. Patterns of migration and difference values after the SMAS-lifting

The procedure matter (Stuzin, 1995) may determine these effects: the tissues are lifted upward and laterally as theoretically positioned on the young people, not modifying the initial volumes of soft tissues and any physical properties of the tissues.

The peculiar properties of soft tissue migration is the ground to doubt about the consistency of modern facial ligaments concept. These suspension ligaments are not distinguished between the ordinary sub-skin fat on computed tomography though the tiny ligamentous structures as the SMAS, superficial leaf of temporal fascia, buccal fat pad capsule can be discerned. The mechanics of interaction between skin, subcutaneous soft tissue, muscular and bony framework is not even, but probably the discrepancy of volume and skin surface migration are based on a sliding of subcutaneous fat on the underlying areolar connective tissue spaces (Mendelson, 2008). The age related changes as sagging and displacement of sub-skin tissues and compartments (Cotofana, 2016, Farkas, 2013, Gierloff, 2012) in gravity test are the consequences of increasing volume migration at gravity test.

The described functional approach allows to assess the mechanical conditions of individual face and evaluate the SMAS-lifting outcomes and efficacy of performed surgery. After sufficient data accumulation, the method of point migration can be used to develop classification of face ptosis grade.

\section{CONCLUSION}

The result of current work is the approach to 3D analysis of gravity ptosis. The detection and matching of marker points were performed automatically by the specifically developed program module. This approach is feasible to analyze the mechanical changes occur with the face in age and after invasive procedures as a SMAS-lifting. The study of tissue migration under the gravity force is the ground for further investigation concerning the aging and rejuvenation procedures.

\section{REFERENCES}

Cotofana, S. et al., 2016. The Anatomy of the Aging Face: A Review. Facial Plastic Surgery, 32(03), pp.253-260.

Farkas, J. P. et al., 2013. The Science and Theory behind Facial Aging. Plastic and Reconstructive Surgery Global Open, 1(1), e8-e15. 
Furnas D., 1994. The superficial musculoaponeurotic plane and the retaining ligaments of the face. In: Psillakis JM Deep Face-lifting Techniques. New York: Thieme Medical Publishers.

Furnas D.W., 1989. The retaining ligaments of the cheek. Plast Reconstr Surg 83:11-6.

Gardetto, A. et al., 2003. Does a superficial musculoaponeurotic system exist in the face and neck? An anatomical study by the tissue plastination technique. Plast Reconstr Surgery, 111(2), pp.664-72.

Gierloff, M. et al., 2012. Aging Changes of the Midfacial Fat Compartments. Plastic and Reconstructive Surgery, 129(1), pp.263-273.

Guryanov, R. A., Guryanov, A. S. (2015). CT anatomy of buccal fat pad and its role in volumetric alterations of face. In: International Archives of the Photogrammetry, Remote Sensing and Spatial Information Sciences - ISPRS Archives (Vol. 40).

Kim, S. J. et al., 2015. Analysis of Age-Related Changes in Asian Facial Skeletons Using 3D Vector Mathematics on Picture Archiving and Communication System Computed Tomography. Yonsei Med J. Sep;56(5):1395-1400

Mendelson, B.C. et al., 2008. Surgical anatomy of the lower face: The premasseter space, the jowl, and the labiomandibular fold. Aesthetic Plastic Surgery, 32(2), pp.185-195.

Ozdemir R. et al., 2002. Anatomicohistologic study of the retaining ligaments of the face and use in face lift: retaining ligament correction and SMAS plication. Plast Reconstr Surg. Sep 15;110(4):1134-47

Ozsoy, U., et al., 2015. Effect of sitting, standing, and supine body positions on facial soft tissue: Detailed 3D analysis. International Journal of Oral and Maxillofacial Surgery, 44(10), 1309-1316.

Santos, D. C. et al., 2016. Suspensory Ligament of the Mammary Gland: A Case Report. Aesthetic Plastic Surgery, 40(1), 98-101.

Stuzin J.M. et al., 1995. Extended SMAS dissection as an approach to midface rejuvenation. Clin Plast Surg. 22(2):295311.

Weaver A.A., et al., 2010. CT based three-dimensional measurement of orbit and eye anthropometry. Invest Ophthalmol Vis Sci. 51(10):4892-7. 